\title{
Open Educational Resources (OER) for Control Systems Engineering: Development Case with LabVIEW, Simulink, and Camtasia
}

\author{
http://dx.doi.org/10.3991/ijep.v2i4.2272 \\ M.Abdulwahed ${ }^{1}$, Z. K. Nagy ${ }^{2 \& 3}$ and A.R. Crawford ${ }^{3}$ \\ ${ }^{1}$ Qatar University, Doha, Qatar \\ 2 Purdue University, West Lafayette, USA \\ ${ }^{3}$ Loughborough University, Loughborough, UK
}

\begin{abstract}
The aim of this paper is to report on the development of control systems open educational resources. The paper reports on two control systems education software: 1A LabVIEW based Control Systems Analysis Toolkit (CSAT) which was developed to assist lecturers in teaching control engineering and students to understand theoretical concepts, and 2- A Process Control Virtual Laboratory (PCVL), developed using LabVIEW. Both software have been created as a stand-alone educational application together with a detailed manual and learning activities. Existing Simulink exercises have been enhanced and specific video tutorials for the Simulink exercises have been developed. Evaluations have been conducted indicating positive impact on students.
\end{abstract}

Index terms-Open Educational Resources (OER); Control Engineering; Interactive Tutorials; Virtual Labs; Computer Simulations

\section{INTRODUCTION}

Control systems is a multidisciplinary engineering subject which is taught in electrical, mechanical, chemical and civil engineering degrees. Control systems subjects involve a considerable mathematical portion which makes it less appealing for some engineering students. One way to make control systems concepts more accessible to engineering students is by using computer simulations and interactive media. Matlab/Simulink and LabVIEW are two software packages that are used widely in control engineering for analysis, simulation and design of control systems. Simulink provides a model building environment that is graphical and more intuitive for engineers. Students can use Simulink to build control systems models, analyse them, change parameters and observe output behaviour graphically without a need to analytically solve mathematical equations. As a result Matlab/Simulink has been used in academia for teaching and learning of control systems. Simulink for control systems is taught in a third year course "Chemical Process Control" within the Chemical Engineering Department at Loughborough University.

LabVIEW provides a sophisticated environment for developing user-friendly engineering software tools and stand-alone executable applications that can be easily run without the need of installing the main development environment, which is not the case with Matlab/Simulink. Despite these benefits, LabVIEW applications in teaching and learning in engineering (including control systems) are significantly less noticeable than those of Matlab/Simulink. LabVIEW can be used for developing stand-alone virtual laboratories and software analysis tools for control systems and has been used within the Chemical Engineering Department, Loughborough University and for developing a Control Systems Analysis Toolkit (CSAT), and for developing a Process Control Virtual Laboratory that demonstrates different concepts of proportional-integral-derivative (PID) control using a tank level control experiment. Multimedia video tutorials were designed to assist in teaching Simulink exercises, and to provide revision resource and some formative assessment of theoretical concepts. The following section provides further details on the development of these resources.

\section{THE APPROACH}

\section{A. Simulink Exercises and Video Tutorials for Control Systems}

Simulink for control systems is being taught within the "Chemical Process Control" module at the Chemical Engineering Department, Loughborough University. The students use Simulink to build control systems models and analyze their behavior. A number of Simulink exercises have to be finalized within two hours of supervised computer laboratory activities. To aid understanding and enable students to undertake activities within the time limits, a number of video tutorials were developed as assistive learning tools to provide guidance for the Simulink exercises at the student's own pace. The video tutorials were developed with Camtasia, a software tool for creating interactive video demonstrations by capturing the desktop screen or used in association with PowerPoint presentations to develop customized videos [1]. The Camtasia development environment provides a number of capabilities/functions to the developer such as creating a table of contents, adding call outs and descriptions, audio and video editing, adding interactive multiple choice questions with feedback, connectivity to virtual learning environments such as Moodle, and final production of the video in a various number of offline and online formats. 


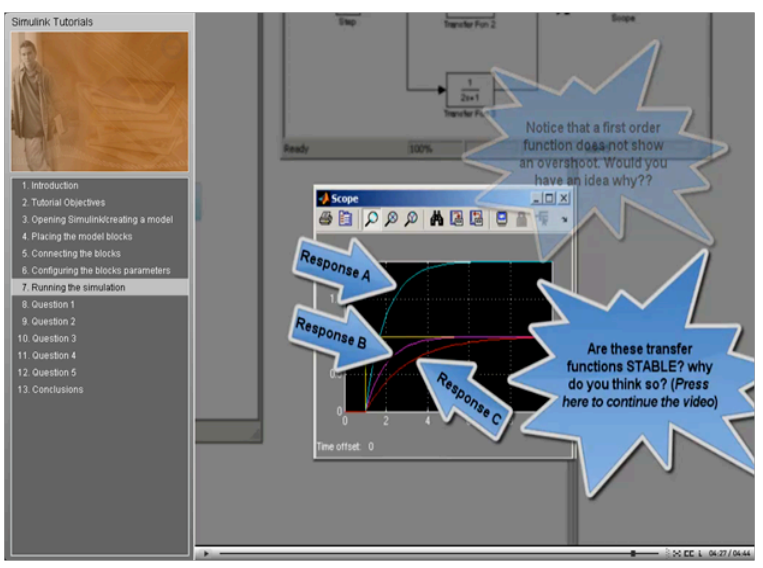

Figure 1. Simulink "Exercise 1" video tutorial developed with Camtasia; a frame with a number of assistive callouts

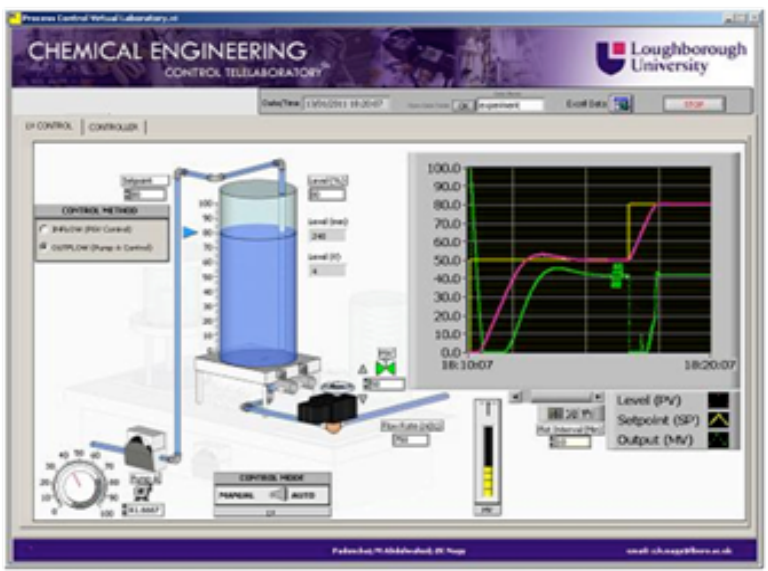

Figure 2. The Graphical User Interface (GUI) of the Process Control Virtual Lab (PCVL)

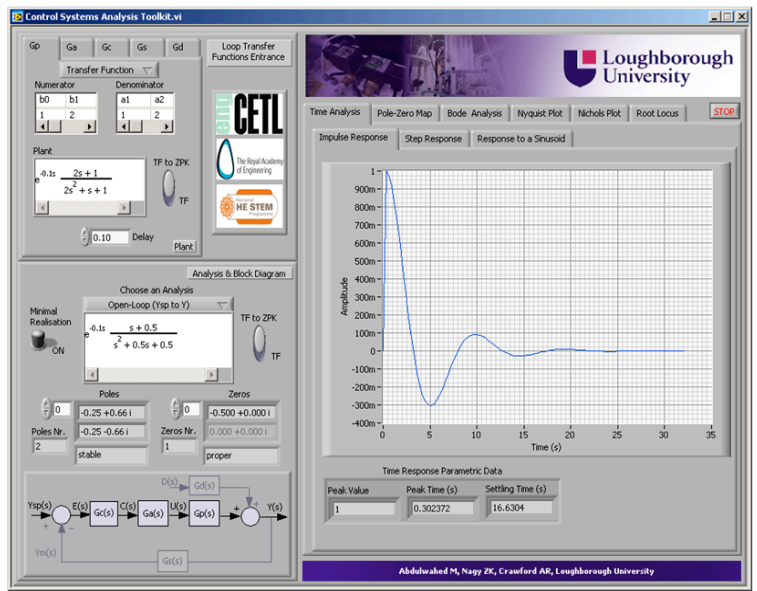

Figure 3. The Graphical User Interface (GUI) of the Control Systems Analysis Toolkit (CSAT)

Seven video tutorials for Simulink were developed, using the functionality of Camtasia. The first video tutorial briefly introduced the Simulink environment to the students while the remainder covered the six Simulink exercises. These exercises aimed to help the students to use
Simulink to enhance conceptual understanding of dynamics and PID control. Each video tutorial included explicit objectives at the beginning together with summary points of what has been covered and the general aims of the next tutorial. Comprehensive interactive descriptions have been added throughout each tutorial using the "Call out" feature of Camtasia, as shown in Figure 1. Most of the video tutorials have been associated with additional interactive multiple choice questions to enhance the conceptual/procedural understanding of the demonstrated topic in the exercise.

\section{B. The Process Control Virtual Laboratory (PCVL)}

The Process Control Virtual Laboratory (PCVL), shown in Figure 2, is educational software programmed in LabVIEW for demonstrating control systems concepts via manipulating a simulated model of a physical process. The software has been developed at Loughborough University to complement hands-on laboratory activities that are performed on Armfield PCT40 experimental rig. The PCVL provides a virtual model of the Armfield PCT40 tank filling process plus additional control and regulation capacities. The PCVL can sometimes be used by control systems students and lecturers as a virtual lab activity; furthermore those who have access to an Armfield PCT40 rig will find the PCVL a valuable addition to the physical rig. The main interface is designed with the vision of providing access to four main experiments: level tank control, pressure control, temperature and flow control, and project work. Currently, the tank level control experiment interface, shown in Figure 2, is active while the rest are to be developed in the future.

The tank level control experiment is a typical process control engineering exemplar used in undergraduate control systems courses. A special and detailed laboratory manual for the tank level control experiment has been customised and provided as a part of this project. The laboratory manual can be used for conducting an instrumentation and control experiment virtually via the PCVL and proximally with the Armfield PCT40 physical rig. The aim of the lab is to familiarise first or second year engineering students with basic concepts of instrumentation and control concepts. The PCVL installer will setup both the PCVL software and the associated laboratory manual.

\section{The Control Systems Analysis Toolkit (CSAT)}

A main objective of this project was to develop LabVIEW based stand-alone educational software to assist in teaching and learning of control systems concepts; the software has been called "Control Systems Analysis Toolkit (CSAT)". The toolkit can be installed and run on stand-alone PCs without the need for a LabVIEW or Matlab/Simulink development environment. The user can perform a number of typical control systems analysis procedures with the CSAT, e.g. stability detection, time analysis such as impulse and step responses, poles and zeros calculation, Bode analysis, Nyquist analysis, Nichols analysis and Root Locus analysis. These procedures can be applied for nine typical control systems transfer functions: 1- Plant, 2- Actuator, 3- Controller, 4- Plant, 5Sensor, 6- Open-Loop with measurements, 7- Open-Loop without measurements, 8- Servo Closed-Loop and 9Regulatory Closed-Loop. 


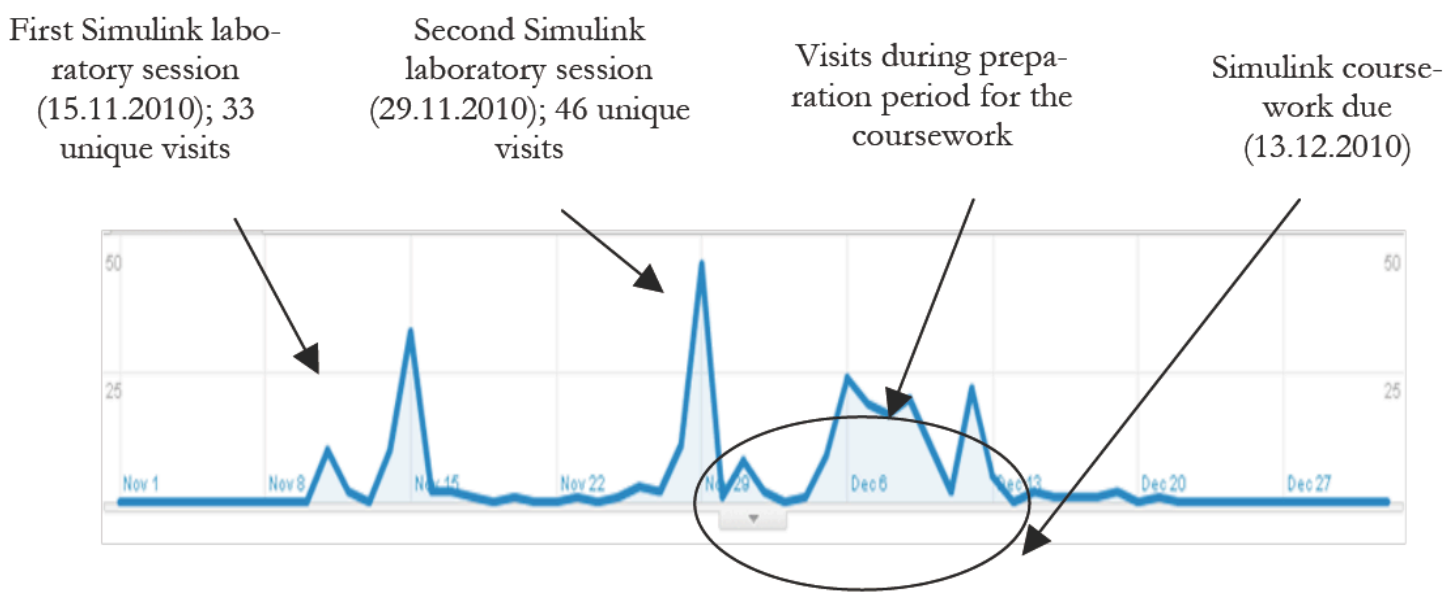

Figure 1. Google analytics of the unique visits of the websiteof the Simulink videao tutorials

The CSAT is designed to be used by students and lecturers for enhancing conceptual understanding of control systems topics. Students for instance, can use the toolkit to test theoretical concepts taught in lectures. Lecturers for instance, can use the toolkit in the classroom for interactively displaying theory whilst lecturing or they can use it as a platform for designing assignments or virtual laboratory work to accompany their modules. The CSAT interface is shown in Figure 3. The CSAT installer will set-up the software executable together with a specially developed user manual and activity exercises.

\section{EVALUATION}

This section details the evaluation of the open educational resources developed within the project including: Simulink computer simulations, video tutorials, the PCVL and the CSAT.

\section{A. Simulink Computer Simulation Exercises}

Simulink laboratory sessions were conducted in semester one of the academic year 2010-2011 for around 50 third year students. The students attended two 1-hour scheduled sessions at the University (the first one on 15th of November and the second one on 29th of November); the students then submitted compulsory Simulink coursework by 13th of December. At the end of the course, a questionnaire was delivered for the students to evaluate their views on using the video tutorials. The students were asked a number of related questions and were asked to rate their opinion on a scale of six points where:

$1=$ "Strongly disagree",

$2=$ "Disagree",

$3=$ "Disagree a little",

$4=$ "Agree a little",

$5=$ "Agree" and

$6=$ "Strongly agree".

Overall the students were positive; the mean average for all questions was considerably above the neutral point (3.5), as shown in Table I. The students found the Simulink exercises:

- helpful in motivating themselves to revise the relevant theory (Q1);

- helpful (highest scored mean) in enhancing conceptual understanding the taught topics (Q2);
- helpful in making the associated mathematics less abstract (Q3);

- they also wanted to be provided with additional Simulink simulations and exercises for self-learning and practice (Q4).

One of the Simulink exercises introduced the practical procedure of tuning PID controllers with Ziegler-Nichols method. The students found:

- this exercise was quite helpful (second highest mean score) in mastering the method (Q5),

- this would not be adequately mastered by ONLY reading the lecture notes $(\mathrm{Q} 6)$.

- they highly valued (second highest mean score) the idea of incorporating theoretical lectures with simulation demonstrations to illustrate the presented theory (Q7).

TABLE I. STUDENTS AVERAGE MEAN RESPONSE TOWARDS SIMULINK VIDEO TUTORIALS.

\begin{tabular}{|l|c|c|}
\hline \multicolumn{1}{|c|}{ Questions } & $\begin{array}{c}\text { Sample } \\
\text { Number }\end{array}$ & Mean \\
\hline $\begin{array}{l}\text { Q1. To which extent do you think that the } \\
\text { Simulink simulation exercises were helpful in } \\
\text { motivating towards revision of the relevant } \\
\text { theory? }\end{array}$ & 33 & 4.85 \\
\hline $\begin{array}{l}\text { Q2. To which extent do you think that the } \\
\text { Simulink simulation exercises were helpful in } \\
\text { enhancing the conceptual understanding of the } \\
\text { topic? }\end{array}$ & 33 & 5.03 \\
\hline $\begin{array}{l}\text { Q3. To which extent do you think that the } \\
\text { Simulink simulation exercises were helpful in } \\
\text { making the associated mathematics less } \\
\text { abstract? }\end{array}$ & 33 & 4.45 \\
\hline $\begin{array}{l}\text { Q4. To which extent do you agree on providing } \\
\text { additional Simulink simulations and exercises } \\
\text { for self-learning and practice? }\end{array}$ & 33 & 4.85 \\
\hline $\begin{array}{l}\text { Q5. To which extent do you think that the } \\
\text { Ziegler-Nichols tuning exercise have enabled } \\
\text { you to master the tuning process? }\end{array}$ & 33 & 4.97 \\
\hline $\begin{array}{l}\text { Q6. To which extent do you think that master- } \\
\text { ing the Ziegler-Nichols tuning process would } \\
\text { not have been adequate by ONLY reading the } \\
\text { lecture notes? }\end{array}$ & 33 & 4.33 \\
\hline $\begin{array}{l}\text { Q7. To which extent do you agree to incorpo- } \\
\text { rate theoretical lectures with simulation } \\
\text { demonstrations to illustrate the presented } \\
\text { theory? }\end{array}$ & 33 & 4.97 \\
\hline
\end{tabular}


TABLE II. STUDENTS AVERAGE MEAN RESPONSE TOWARDS SIMULINK SIMULATION EXERCISES.

\begin{tabular}{|l|c|c|}
\hline \multicolumn{1}{|c|}{ Questions } & $\begin{array}{c}\text { Sample } \\
\text { Num- } \\
\text { ber }\end{array}$ & Mean \\
\hline $\begin{array}{l}\text { Q1. Overall, to which extent do you think the } \\
\text { videos are helpful for preparation before the } \\
\text { Simulink tutorial sessions at the computing } \\
\text { laboratory? }\end{array}$ & 31 & 4.97 \\
\hline $\begin{array}{l}\text { Q2. To which extent do you think that the } \\
\text { videos are helpful for additional practice after } \\
\text { the two Simulink tutorial sessions at the } \\
\text { computing laboratory? }\end{array}$ & 31 & 4.74 \\
\hline $\begin{array}{l}\text { Q3. To which extent do you think that the } \\
\text { video tutorials are helpful for revision for } \\
\text { preparing your Simulink coursework? }\end{array}$ & 31 & 4.71 \\
\hline $\begin{array}{l}\text { Q4. To which extent do you agree that the } \\
\text { pace of the videos was acceptable? }\end{array}$ & 31 & 4.84 \\
\hline $\begin{array}{l}\text { Q5. To which extent do you do you agree that } \\
\text { descriptions in the video tutorials has been } \\
\text { adequate? }\end{array}$ & 31 & 4.71 \\
\hline $\begin{array}{l}\text { Q6. To which extent do you think that the } \\
\text { Quizzes by the end of the videos and their } \\
\text { feedback were useful in enhancing your } \\
\text { conceptual understanding of the topic? }\end{array}$ & 28 & 4.46 \\
\hline $\begin{array}{l}\text { Q7. To which extent do you agree on provid- } \\
\text { ing extra online multiple choice Quizzes and } \\
\text { feedback in relation with other concepts and } \\
\text { topics of the module? }\end{array}$ & 30 & 5.13 \\
\hline $\begin{array}{l}\text { Q8. To which extent do you agree on record- } \\
\text { ing video tutorials of the lectures and make it } \\
\text { available online? }\end{array}$ & 30 & 4.97 \\
\hline
\end{tabular}

TABLE III. STUDENTS AVERAGE MEAN RESPONSE TOWARDS PROVIDING A SOFTWARE TOOL SUCH AS THE CSAT FOR INTERACTIVE SIMULATIONS OF CONTROL SYSTEMS TOPICS: FIRST \& SECOND ORDER SYSTEMS; ZEROS, POLES, AND TIME RESPONSES; FREQUENCY RESPONSE; AND CONTROLLER DESIGN

\begin{tabular}{|l|c|c|}
\hline \multicolumn{1}{|c|}{$\begin{array}{c}\text { Features of the } \\
\text { Proposed Software }\end{array}$} & $\begin{array}{c}\text { Sample } \\
\text { Number }\end{array}$ & Mean \\
\hline $\begin{array}{l}\text { First order systems } \\
\text { dynamics }\end{array}$ & 31 & 5.19 \\
\hline $\begin{array}{l}\text { Second order systems } \\
\text { dynamics }\end{array}$ & 31 & 5.13 \\
\hline $\begin{array}{l}\text { Zeros, poles and time } \\
\text { responses }\end{array}$ & 31 & 5.13 \\
\hline Frequency response & 31 & 5.13 \\
\hline Controller design & 31 & 5.26 \\
\hline
\end{tabular}

\section{B. Video Tutorials}

The videos were provided to the students of the "Chemical Process Control" module to use online as an assistive tool for the two scheduled Simulink laboratory sessions in the winter semester of the academic year 20102011. In the final module questionnaire, students were asked their opinion towards the associated video tutorials. The students' responses were in general positive with an average mean higher than the neutral point (3.5) as shown in Table II. The students found the videos helpful in preparing before the scheduled sessions at the University and for additional practice after the sessions. They found the videos helpful for revision of Simulink before preparing for the compulsory coursework; the videos' pace, description and associated multiple choice questions were found to be satisfactory. The highest mean of students' response was when they were asked about their opinion of recording video tutorials of the lectures and making them available online, see Q8 in Table II. The students were also very positive towards the idea of providing extra online multiple choice quizzes and feedback in relation with other concepts and topics of the module. Google analytics of the website of the video tutorials, see Figure 4 , shows two main peaks at 15 th and 29th of November (the scheduled Simulink labs).

A considerable number of log-ins to the tutorials website can be noted for the period from 29th of November to 13th of December (Simulink coursework submission deadline), indicating that many students returned to review the video tutorials in order to undertake the Simulink coursework.

An E-Learning Officer and Camtasia developer from the Engineering Centre for Excellence in Teaching and Learning at Loughborough University was asked to watch the videos and qualitatively evaluate them. She had no previous experience of Simulink, but found the videos quite helpful in learning about the Simulink environment. She positively commented on "User Experience" characteristics associated with the videos such as pace, content, and overall appearance. Ivan Moore from the Royal Academy of Engineering expressed similar positive opinions while viewing the videos. Additional feedback from Jenny and Ivan was considered by the project team and incorporated within the final production of the videos.

\section{The Control Systems Analysis Toolkit (CSAT)}

The CSAT development was one of the main objectives of this project, the tool deployment into teaching and learning is planned to take place from the academic year 2011/2012; hence evaluation was not a target. However, since the CSAT aimed to provide students with standalone interactive educational software for facilitating conceptual understanding of control systems, students were asked their opinion of providing them with stand-alone software for analysis of different aspects of control systems. Students were very positive towards being provided with a tool such as the CSAT as reflected by the average means in Table III.

\section{The Process Control Virtual Laboratory (PCVL)}

Earlier versions of the PCVL were originally developed and evaluated during the period from 2007 till 2010. Virtual laboratories were used in a variety of pedagogical studies, mainly with second year students of the "Instrumentation and Control" module at the Chemical Engineering Department, Loughborough University. A novel constructivist pedagogical model whereby the virtual laboratory plays an essential component was proposed. Using the virtual laboratory in a preparation session before a hands-on laboratory was found to have a statistically significant positive impact on students' learning outcomes in pre- and post-lab tests, laboratory report quality and the module final exam mark. Further comprehensive details of the PCVL pedagogical evaluations can be found in [2], [3].

\section{Discussion AND FURTHER DEVElopMENT}

The positive impact of using interactive teaching aids (e.g. computer simulations, interactive video tutorials and virtual labs) on engineering students' attitudes and learn- 
ing outcomes can be explained from many perspectives. According to the dual coding theory of information cognition, the human mind perceives and stores verbal and visual information through two distinct channels [4]. The implication on educational processes is that incorporating visual objects with a written text (e.g. the lab manual) can lead to better learning [5]. For instance, Simulink exercises help visualise the mathematical equations; the virtual lab helps to visualise the experimental rig in a simplified way by show the experimental data in a series of graphs.

The VARK learning styles model suggests that there are four main learning styles: Visual, Aural, Read/write and Kinaesthetic [6]. Learning from written materials such as lecture notes and lab manuals could be suitable for those students who have a strong read/write learning style. However, combining the computer simulations and/or virtual with written materials accommodates those students who have visual and kinaesthetic learning styles. The learning pyramid model [7] suggests that information retention rates are different depending on the learning method (5\% lecture, $10 \%$ reading, $20 \%$ audio/visual, $30 \%$ demonstration, $50 \%$ discussion group, $75 \%$ practise by doing, 90\% teaching others). Computer simulations and virtual labs provide the opportunity to learn by doing and hence results in much higher knowledge retention.

Open educational resources enable other educators and students to use existing available material and to customise/integrate them for their needs. They also minimise costs by reducing the time and money invested to develop resources from scratch. In this project, a number of educational resources have been developed and made available online (together with existing materials). These resources included:

- computer simulations developed with Simulink,

- associated video tutorials, a virtual laboratory,

- a control systems analysis toolkit,

- written manuals and

- activity exercises.

All of these open educational resources are available through http://www.ilough-lab.com. Since dissemination (November 2010 for Simulink tutorials, and January 2011 for the PCVL and the CSAT) at the ilough-lab.com, the following visits count (from the UK and internationally) have been registered: 582 visits for the Simulink video tutorials, 105 visits for the CSAT webpage, 101 visits for the PCVL.

\section{ACKNOWLEDGMENT}

Funding of developments presented in this paper from the Royal Academy of Engineering; the Engineering Centre for Excellence in Teaching and Learning and the Chemical Engineering Department, both at Loughborough University; and the Engineering Subject Centre is greatly acknowledged.

\section{REFERENCES}

[1] S. R. Mark, "Personalizing the online classroom using TechSmith's Camtasia or Microsoft's Windows Media Encoder," Online Classroom, vol. 4, pp. 4-5, December 2004.

[2] M. Abdulwahed, and Z. K. Nagy, “Applying Kolb's experiential learning on laboratory education," Journal of Engineering Education, vol. 98, pp. 283-294, July 2009.

[3] M. Abdulwahed, and Z. K. Nagy, "The TriLab, a novel ICT based triple access mode laboratory education model," Computers \& Education, vol. 56, pp. 262-274, January 2011. http://dx.doi.org/10.1016/j.compedu.2010.07.023

[4] J. M. Clark, and A. Paivio, "Dual coding theory and education," Educational Psychology Review, vol. 3, pp. 149-210, July 1991. http://dx.doi.org/10.1007/BF01320076

[5] R. E. Slavin, Educational psychology: Theory and Practice, $8^{\text {th }}$ ed., Prentice Hall, 2006.

[6] N. D. Fleming, and C. Mills, "Not another inventory, rather a catalyst for reflection," To Improve the Academy, vol. 11, pp. 133-149, 1992.

[7] G. W. H. Weenk, Learning pyramid, Educational Center, University of Twente, 1989.

\section{AUTHORS}

M. Abdulwahed is with the Dean's Office, College of Engineering, Qatar University, Doha, Qatar (e-mail: m.abdulwahed@qu.edu.qa).

Z.K. Nagy ., was with the Chemical Engineering Department, Loughborough University, Loughborough LE11 3TU. He is now with the School of Chemical Engineering, Purdue University, West Lafayette, IN 47907-2100,USA (e-mail: zknagy@purdue.edu).

A.R. Crawford is with the Civil Engineering Department, Loughborough University, Loughborough LE11 3TU, UK (e-mail: a.r.crawford@lboro.ac.uk)

This article is an extended version of a paper presented at IEEE International Conference on Teaching, Assessment and Learning for Engineering 2012 (TALE2012), held 20-23 August 2012, at The Hong Kong Polytechnic University, Hong Kong. Received 14 September 2012. Published as resubmitted by the authors 5 October 2012. 